\title{
LA LIBERTAD DE CONCIENCIA EN LA CONSTITUCIÓN ESPAÑOLA
}

\author{
JOSÉ MARTÍNEZ DE PISÓN \\ Catedrático de Filosofía del Derecho \\ Universidad de La Rioja
}

1.- El Departamento de Derecho de la Universidad de La Rioja rinde, sin duda, un sincero y merecido homenaje a la Constitución española de 1978 al dedicar de forma monográfica su Seminario Permanente de Profesores del año 2003 a la celebración del 25 aniversario de su elaboración y aprobación. Antes de entrar en más detalles y en desarrollar mi posición sobre el tema que nos ocupa, es decir, la libertad de conciencia en la Constitución y, en particular, el análisis de su artículo16, quisiera dar la enhorabuena al Departamento de Derecho por esta iniciativa, así como agradecer a su coordinador el que me haya invitado a participar en este interesante Seminario.

La Constitución de 1978 ha sido el texto constitucional que ha permitido un largo período de normalidad política en la historia española de los dos últimos siglos en el cual el país y la sociedad parecen haber superado los viejos problemas e iniciado un proceso de modernización y de incorporación a las sociedades más avanzadas. Por supuesto, el texto por sí mismo no ha sido garantía del éxito de este proceso. Si todo esto ha sido posible ha sido por lo que simboliza el texto constitucional: esto es, un gran pacto sobre las reglas básicas que deben guiar la convivencia entre los españoles y sobre las instituciones de la organización política. Estas reglas, por su dimensión y su función, lógicamente, recogen unos principios y unas normas generales a partir de los cuales resolver nuestras diferencias y cuanto problemas puedan surgir. No es posible, sin embargo, concretar más aquí y comentar qué reglas son éstas, pues ello me llevaría demasiado tiempo e impediría entrar en el asunto por el que se me ha invitado. No obstante, sí insistir en que una gran 
responsabilidad de que el proceso al que me refería antes tuviese éxito ha surgido de la voluntad de todos de que esas reglas constituyan realmente la piedra angular de una convivencia en paz y en un sistema democrático.

Quisiera también señalar desde un principio que, a pesar de las evidentes ventajas que han deparado los años de vigencia de la Constitución, en la actualidad se la está sometiendo a tensiones y fuerzas contrarias que ensombrece el panorama de estos últimos lustros. Y que en algunos casos, principalmente, a partir de posiciones que deberían ser más cautelosas, se le somete a un uso impropio dando lugar a lecturas que me gustan poco y que cada vez están teniendo también una clara influencia sobre una revisión de acontecimientos importantes de nuestra historia: la República, la insurrección militar contra la misma que dio lugar a la Guerra Civil, o sobre la pervivencia y legitimidad de la Dictadura y su continuidad en el actual régimen democrático. Todo esto me parece muy preocupante. Por ello, quisiera pedir a los gobernantes y a la clase política en general que procuren evitar ideas, posiciones y políticas que debieran estar encerradas en el baúl de los recuerdos.

2.- Uno de los elementos característicos de la Constitución de 1978 es que, tras la experiencia republicana, consagra la libertad de conciencia. La historia constitucional española, desde la de 1812, es una historia -y hay que decirlo con todas las letras- de intolerancia. Salvo la Constitución de 1931, todas las demás recogen la confesionalidad estatal: la religión católica es no sólo la religión de los españoles, sino también del Estado. La ya mencionada Constitución de 1812, considerada por los comentaristas la más progresista, fue sin embargo en este punto bastante reaccionaria: no sólo declara que la religión católica es la de los españoles, sino que, además, proclama que lo será perpetuamente. Esto no es sino un ejemplo de las expresión de confesionalidad estatal que recogen nuestros textos constitucionales históricos y que reflejan el papel central de la Iglesia católica en la sociedad española, por encima de ideas y creencias. Monopolio ideológico que se plasmará en todos los aspectos de la vida social y que será caballo de batalla entre los partidos políticos, entre quienes quieren que se siga manteniendo la confesionalidad y quienes defienden la tolerancia ideológica y el reconocimiento de la libertad de pensamiento y de conciencia. Esta polarización en torno a la "primera de las libertades", sin duda, planeará sobre el período de la transición y sobre el debate constituyente.

Refiriéndonos, más en concreto, al artículo 16 de la Constitución, a primera vista, estaríamos todos de acuerdo en que recoge, en sus diferentes apartados, la aconfesionalidad del Estado, así como la libertad de conciencia bajo la redacción en el caso de esta última de que "se garantiza la libertad ideológica, religiosa y de culto" de los españoles. Sin embargo, desde mi perspectiva, este juicio no completaría todas las aristas de un artículo más complejo de lo que a primera vista pudiera parecer. Si bien es cierto que en su apartado primero recoge, en una redacción no muy afortunada, la libertad ideológica y religiosa, en el segundo, especifica que "nadie podrá ser obligado a declarar sobre su ideología, religión o creencias" y en el tercero la declaración de aconfesionalidad estatal, pues "ninguna confesión tendrá carácter estatal. Los poderes públicos tendrán en cuenta las creencias religiosas de la sociedad española y mantendrán las consiguientes relaciones de cooperación con la Iglesia católica y las demás confesiones". 
La verdad es que creo que la redacción escogida no es la más acertada para reflejar la aconfesionalidad estatal, así como una visión laica de la sociedad. Quiero aclarar que mi juicios sobre este artículo se fundamentan en que la Constitución debería haber plasmas el principio de neutralidad estatal en manera de creencias. Dicho de otra manera, que el mundo de las creencias es el mundo de la conciencia y que en este ámbito no deben admitirse injerencias de los poderes públicos. En la historia europea de los últimos siglos hay ejemplos claros de las consecuencias de utilizar al Estado como instrumento de imposición de creencias o de una concreta religión. Como punto de partida, por tanto, el reconocimiento de que el ámbito estatal y el religioso o eclesial son ámbitos distintos de manera que no puede utilizarse recursos públicos para propagar o realizar cultos de una religión. $\mathrm{O}$, si se utilizan medios estatales, debe hacerse en condiciones de igualdad entre todas las creencias, sin discriminación de ningún tipo. Lo cual no supone la negación del hecho religioso o de su importancia en la sociedad, sino su circunscripción al ámbito que le es propio.

3.- En consecuencia, mi opinión del artículo 16 de la Constitución es que es un artículo formalmente correcto pero con muchos matices. Este juicio requiere importantes precisiones. Al menos, señalar dos. La primera ya la he apuntado anteriormente. Me parece que los constituyentes no acertaron con la denominación del derecho que querían recoger. El art. 13.1 especifica que se garantiza la libertad ideológica, religiosa y de cultos que es una terminología que se adecua a la historia y a la teoría de los derechos. No recoge expresamente la libertad de conciencia, ni la de pensamiento. Por ello, los especialistas se han tenido que ocupar de debatir, razonar y justificar si realmente estas libertades están recogidas en la constitución e, incluso, qué derechos se reconocen en ese artículo. Y, por cierto, no falta quién duda de que la voluntad de los constituyentes fuese recoger esos derechos. El defecto en la terminología, pues, no es una mera cuestión nominalista, sino es un asunto de más calado y que afecta a la especificación de los derechos fundamentales recogidos en la Constitución. Da la impresión de que no se quería reconocer el derecho a la libertad de pensamiento y de conciencia o que, con el empleo del término "libertad ideológica" se pretendía devaluar a un importante derecho. Hubiera sido más correcto que se hubiera utilizado el de "derecho a la libertad de pensamiento, conciencia y de religión" que es, en última instancia, el utilizado por los textos internacionales relativos a los derechos humanos desde que se aprobara la Declaración Universal de Derechos Humanos.

De mayores consecuencias me parece la redacción del apartado 3 del artículo 16 en el que se menciona a la Iglesia católica justo nada más recoger la aconfesionalidad estatal. Esta mención y sus consecuencias pone en cuestión esta aconfesionalidad hasta el punto de que puede afirmarse, como se hizo en el debate constituyente, que, de acuerdo a la previsión de este artículo, el Estado español es formalmente aconfesional, aunque materialmente no lo sea al mantener la Iglesia católica una posición de monopolio y de privilegio en amplias esferas de la vida social y al ser favorecida por los poderes públicos, con una clara discriminación hacia otras confesiones y otras creencias. En dicho debate no fue raro que desde la tribuna se denunciara la confesionalidad solapada que entrañaba dicha mención. 
De hecho, durante el debate constituyente, fueron numerosas las presiones de las autoridades eclesiales para que la Constitución finalmente aprobada recogiera alguna de las tesis de la Conferencia episcopal, máximo órgano en España de la Iglesia católica. La más sonada tuvo lugar con ocasión de la filtración en noviembre de 1977 de un primer borrador de Constitución en el que se recogía la aconfesionalidad estatal en el artículo 3. La jerarquía católica ya entonces expuso sus tres reivindicaciones: que la aconfesionalidad no se incluyera en el artículo 3; que hubiera en el texto constitucional una mención a la Iglesia católica y a su presencia en la sociedad española; y que se recogiera la libertad de enseñanza con expreso reconocimiento del derecho a crear centros docentes y el derecho de los padres a escoger la formación religiosa de sus hijos. El texto de 1978 refleja fielmente estas peticiones.

Hay que anotar que, si bien el artículo 16 ya fue polémico en su elaboración, los derechos educativos no lo fueron menos. En el debate constituyente, se enfrentaron dos posiciones muy diferentes en relación con estos derechos. Los sectores de izquierda mantenían el viejo proyecto de una escuela pública, universal y gratuita, mientras que el conservador defendía los centros privados y, en particular, la secular posición privilegiada de la Iglesia católica. Los derechos educativos fueron un auténtico escollo en el proceso de elaboración de la Constitución hasta el punto de que el ponente socialista abandonó la Ponencia a la vista de la imposibilidad de un consenso. Los derechos educativos estuvieron a punto de romper el consenso constitucional. Finalmente, éste y otros aspectos fueron objeto de negociación entre los partidos mayoritarios lo que posibilitó la conclusión de proceso y la aprobación final de la Constitución. Los derechos educativos se recogieron un largo y complejo artículo 27 en el que, entre otras cosas, se daba plena satisfacción a la Iglesia católica, como sucediera también con el artículo 16.3.

4.- Estos argumentos son, pues, unas buenas razones para justificar la confesionalidad encubierta del Estado español. A ellos hay que sumar otro dato que no puede pasar desapercibido para comprender la superioridad de la Iglesia católica en la sociedad española muy por encima de otras confesiones o creencias. Me refiero al hecho de que, al mismo tiempo que tenía lugar el debate constituyente y, en consecuencia, se producían estos acontecimientos, el gobierno de UCD negoció con la Santa Sede el marco legal que debía regir a la Iglesia católica en su relación con el Estado. El resultado fueron los Acuerdos de enero de 1979, que por pudor aparecieron tras la publicación de la Constitución, para que no quedase de manifiesto que, en realidad, establecía un estatuto especial, incluso paraconstitucional, para la Iglesia católica. Estos Acuerdos supusieron la derogación del Concordato franquista de 1953 y establecieron el marco para la financiación de la Iglesia católica, el reconocimiento de su posición privilegiada en la enseñanza y su puesto en el ejército. La forma elegida para su formalización fue la de un tratado internacional lo que confirmaba la intangibilidad del estatuto especial para la Iglesia católica.

El esquema diseñado por los responsables de la UCD en las nuevas relaciones EstadoIglesia quedaba cerrado con la elaboración y aprobación de la Ley Orgánica de la Libertad Religiosa que establecía el marco legal general para el resto de las confesiones religiosas. Así fue defendido por diferentes especialistas, aunque con el tiempo la práctica ha ido 
cambiando un poco las cosas. La Iglesia católica ha utilizado las previsiones de esta ley orgánica cuando lo ha estimado oportuno.

5.- En última instancia, la aconfesionalidad del Estado no sólo está puesta en duda por una deficiente redacción del artículo 16 de la Constitución. Su apartado 3 y la mención a la obligación de los poderes públicos de mantener relaciones de cooperación con la Iglesia católica ha supuesto de hecho que ésta tuviera durante estos años una posición privilegiada. Por supuesto, avalada además por los Acuerdos de 1979. Las demás confesiones no han gozado ni siquiera de una claridad en el estatuto que debe regir sus relaciones con el Estado. Los acuerdos con los representantes de los evangelistas, del islam y de lo judíos no se firmaron hasta 1992 y su regulación está a años luz de los Acuerdos de la Santa Sede en lo que se refiere a financiación, exenciones fiscales o su implantación en la enseñanza, etc.

Con ser ésta ya de por sí una violación del principio de no discriminación por razón de la religión, lo más grave ha sucedido en el último lustro. El artículo 16.3 utilizado por un gobierno conservador con mayoría absoluta ha permitido clarísimas violaciones al principio de igualdad como al principio de aconfesionalidad. Baste con mencionar cuatro ejemplos. Primeramente, ha permitido concertar colegios que no cumplen los requisitos de la LOGSE, en particular, el de no discriminación por razón del sexo. En efecto, el gobierno conservador ha permitido que se suscriba conciertos -lo que quiere decir que se disfrute de dinero de los presupuestos del Estado-, a colegios que segregan a los estudiantes por razón del sexo. En segundo lugar, financia anualmente a la Iglesia católica -en particular, los gastos de la Conferencia Episcopal- más allá del dinero que los católicos destinan en el impuesto sobre la renta a la misma. La financiación de una confesión con cargo a los presupuestos estatales es ya de por sí una prueba de su confesionalidad. En tercer lugar, el gobierno conservador ha implantado la asignatura de religión cuyos contenidos son supervisados por la autoridad eclesial como asignatura obligatoria que influye en el currículo de los estudiantes. Finalmente, además de todo esto, el Estado se ha comprometido a pagar los profesores que impartan esta asignatura de religión y que son designados anualmente por cada obispo. No hace falta ser más explícito en cuál es el contenido de la asignatura de religión que se va a impartir tanto en los colegios públicos como privados.

Muchas gracias 